\title{
Cell Clusters in Cancer Metastasis: A Mini Review
}

\section{Steven Oppenheimer}

Department of Biology and Center for Cancer and Developmental Biology, California State University, Northridge, California, United States

\section{Email address:}

steven.oppenheimer@csun.edu

\section{To cite this article:}

Steven Oppenheimer. Cell Clusters in Cancer Metastasis: A Mini Review. American Journal of Applied Scientific Research. Vol. 6, No. 2, 2020, pp. 43-45. doi: 10.11648/j.ajasr.20200602.13

Received: April 20, 2020; Accepted: May 7, 2020; Published: May 19, 2020

\begin{abstract}
Evidence is accumulating that suggests that cancer cell clusters are more likely to lead to metastatic lesions than are single cells. This mini-review explores this issue by examining evidence that indicates that cell clusters possess altered genes and metabolism that promote metastasis. When clusters are disaggregated, the resulting single cells often lose the altered properties characteristic of when they were in clusters. When cluster disrupting agents were injected into mice, metastasis was reduced. Cluster disaggregating agents are described and mechanisms of action of these compounds are explored. Using these agents to target cell clusters might offer a useful therapeutic approach in the treatment of cancer. Cell clusters are also involved in thrombocytosis and biofilm infectivity as well as cancer spread and cluster disrupting agents might be very useful in treating some human conditions in addition to cancer spread. Assays that examine the effectiveness of cluster disrupting agents are also described.
\end{abstract}

Keywords: Clustered Cancer Cells, Cancer Metastasis, Cluster Disrupting Agents

\section{Introduction}

The cellular basis of cancer metastasis is not well understood but many studies, some involving cell clusters in the metastatic process, have been reported for decades [1]. Exciting work has been more recently done exploring the issue of what is more likely to give rise to metastatic lesions, single circulating cancer cells or cell clusters [2-13]. Detailed investigations that quantitatively assess the likelihood of single cancer cells versus clusters of cancer cells in causing metastatic lesions are described [2]. The molecular characteristics of cell clusters versus single cells are compared and how these characteristics change when clusters are disaggregated is discussed [2-13]. This mini-review will explore the issue of cell clusters as causes of metastatic lesions and new therapeutic approaches for treating cancer based on this concept are discussed. Cell cluster disrupting agents and their mechanisms of action are described [14-16].

\section{Experimental Procedure}

Experiments will be presented that utilize cell culture, assays that identify compounds that disaggregate cell clusters, kinetic assays that measure the effects of cell cluster disrupting agents, in vivo injections in mice, metabolic and DNA methylation assays, and statistical evaluations of results.

\section{Results and Discussion}

In experiments with mice Aceto, et al. [2] calculated that a circulating cancer cell cluster was about 50 times more likely to give rise to a metastasis than a single cell. They found in 323 metastases 171 were derived from clusters while 152 were derived from single cells. They demonstrated this using antibodies that could distinguish between metastases derived from clusters versus single cells. The 50 times figure is based on the finding that clusters were much rarer than single cells [2]. Numerically $2.6 \%$ cell clusters (65) versus $97.4 \%$ (2486) single cells indicated that clusters were much rarer than single cells (2). These figures documented the calculation of the rarity of cell clusters in causing metastatic lesions. This calculation is the basis for the widely reported contention that cancer cell clusters yield more metastatic lesions than single cancer cells, opening up possibilities for targeting cancer cell clusters as a therapeutic approach for treating cancer.

It is unclear how cancer cell clusters lead to more metastases than single cells. There are a number of possibilities. One study suggests that clusters might produce 
less of cell damaging reactive oxygen species, such as peroxides, superoxides, hydroxyl radicals, singlet oxygen and alpha oxygen [3]. Plakoglobin and keratin 14 are more highly expressed in clusters compared to single cells [4] and claudin-11, a protein in tight junctions, was expressed in cell clusters, while E-cadherin, also expressed in clusters, might support cluster survival during metastasis [5].

Cell clustering results in DNA hypomethylation and hypermethylation of specific sites involved in cell proliferation [6]. When clusters were dissociated into single cells the methylation profiles reversed [6]. In some cancers cells in clusters are connected by plakoglobin and CD44 [7, 8], while in others claudin 11 helps cells in clusters adhere [9]. Increased cell-cell attachments are proposed to help cell clusters maintain metastatic properties. Keratin 14 is highly expressed in clusters. Suppression of keratin 14 expression resulted in reduced metastasis. It is believed that suppression of keratin 14 disrupts the activity of genes such as tenacin C, Jagged 1, and epiregulin [4]. Cancer cell clusters also overexpressed transcription factor XBP1, protein disulfide isomerase AGR2, epidermal growth factor receptor HER 3, inhibitor of matrix metalloproteinases TIMP-1, plasminogen activator SERPINE 1/PAI-1, antiapoptotic factor BCL 2 and other genes [10-13]. Clustered breast cancer cells hypomethylate OCT4, SOX2, NANOG and SIN3A genes involved in cell proliferation, while cell clusters hypermethylate polycomb genes implicated in chromatin changes and blocking of cell differentiation [6]. Cells in clusters may be more protected than single cells from the hostile environment in the blood [1], based on their location.

Many compounds were tested on cell clusters. Of 2486 compounds most had no effect on cluster size [6]. Two families of compounds decreased mean cluster size of human breast cancer cells in culture. These included the sodium/potassium-ATPase inhibitors digitoxin and ouabain and tubulin binding agents vincristine sulfate, rigosertib, colchicine, and podofilox [6]. Treating cell clusters with digitoxin or oubain caused their dissociation while maintaining cell viability and allowing cell proliferation and changes in DNA methylation. Increased intracellular calcium concentration, caused by these compounds occurred, that appeared to lead to an inability of the cancer cells to form functional cell-cell junctions $[6,14,15]$. This appeared to be a mechanism of action of digitoxin and oubain $[6,14,15]$.

The compounds that dissociated cell clusters in vitro were tested in vivo. Oubain treatment reduced cell clusters, increased single cell numbers and reduced metastatic lesions in mice [6]. Oubain and digitoxin are normally used in the treatment of hypotension and cardiac arrhythmias by inhibiting sodium/potassium ATPase [14-16]. These compounds may be useful in reducing metastasis in humans.

Two recent papers reported in this journal $[17,18]$ provide a different approach to disaggregate cell clumps. Using a kinetic assay that examines cells and cell clumps from 0 time to $60 \mathrm{~min}$, two reagents were found that disaggregate fixed yeast cell clumps, sodium citrate [17], a known human anticoagulant [19] and sodium sulfate [18]. While fixed yeast are not cancer cells, their surface properties are similar to live yeast and human cells [20]. This fixed yeast model could identify unclumping reagents that may be useful in treating human cancer as well as thrombocytosis and biofilm infectivity $[17,19,21]$. Thrombocytosis can lead to heart attacks and strokes and biofilms can lead to major infections. Steve Oppenheimer, a Fellow of the American Association for the Advancement of Science, author of this mini-review, received a U.S. Presidential Award from President Obama at the White House, for mentoring the research of hundreds of students whose career outcomes were well documented [22]. This fixed yeast kinetic assay helped facilitate the research of hundreds of students.

\section{Conclusions}

This mini-review provides evidence that cancer cell clusters give rise to metastases at a higher frequency than do single cells and that cancer cluster disrupting agents may offer a useful approach for treating spread cancer.

\section{References}

[1] S. B. Oppenheimer Cellular basis of cancer metastasis Acta Histochem 108 (2006), pp. 327-334.

[2] N. Aceto, A. Bardia, D. T. Miyamoto, M. C. Donandson, B. S. Wittner, J. A. Spencer, M. Yu, A. Pely, A. Engstrom, H. Zhu, B. W. Brannigan, R. Kapur, S. L. Stott, T. Shioda, S. Ramaswamy, D. T. Ting, C. P. Lin, M. Toner, D. A. Haber, S. Maheswaran Circulating tumor cell clusters are oligoclonal precursors of breast cancer metastasis Cell, 28 (2014), pp. $1110-1122$.

[3] C. F. Laqbuschagne, E. C. Cheung, J. Blagih, M. C.. Domart, K. H. Vousden Cell clustering promotes a metabolic switch that supports metastatic colonization Cell Metab 30 (2019), pp. 720-734.

[4] Cheung K. J, Padmanaban V, Silvestri V, Schipper K, Cohen J. D, Fairchild A. N, M. A. Gorin, J. E. Verdone, K. J. Pienta, J. S. Bader, A. J. Ewald Polyclonal breast cancer metastases arise from collective dissemination of keratin 14-expressing tumor cell clusters. Proc Natl Acad Sci U S A. 113 (2016) 854-63.

[5] V. Padmanaban, I. Krol, Y. Suhail, B. M. Szczerba, N. Aceto, J. S. Bader, A. J. Ewald E-cadherin is required for metastasis in multiple models of breast cancer Nature 573 (2019), pp. 439-444.

[6] Gkountela S, Castro-Giner F, Szczerba BM, Vetter M, Landin J, Scherrer R, Krol I, Scheidmann MC, Beisel C, Stimimann CU, Kurzeder C, Heinzelmann-Schwarz V, Rochlitz C, Weber WP', Aceto N. Circulating tumor cell clustering shapes DNA methylation to enable metastasis seeding. Cell 176 (2019) pp. 98-112.

[7] Liu X, Taftaf R, Kawaguchi M, Chang $\mathrm{YF}^{3}$, Chen W, Entenberg D, Zhang Y, Gerratana L, Huang S, Patel DB, Tsui E, Adorno-Cruz V, Chirieleison SM, Cao Y, Harney AS, Patel S, Patsialou A, Shen Y, Avril S, Gilmore HL, Lathia JD, Abbott DW, Cristofanilli M, Condeelis JS, Liu H Homophilic CD44 interactions mediate tumor cell aggregation and polyclonal metastasis in patient-derived breast cancer models. Cancer Discov. 9 (2019) pp. 96-113. 
[8] M Kawaguchi, N Dashzeveg, Y Cao, Y Jia, X Liu, Y Shen, H Liu Extracellular Domains I and II of cell-surface glycoprotein CD44 mediate its trans-homophilic dimerization and tumor cluster aggregation. J Biol Chem 10 (2020) RA 119.010252 .

[9] Li CF, Chen JY, Ho YH, Hsu WH, Wu LC, Lan HY Snailinduced claudin-11 prompts collective migration for tumour progression. Nat Cell Biol. 21 (2019) pp. 251-62.

[10] P. McDonel, J. Demmers, D. W. Tan, F. Watt, B. D. Hendrich Sin $3 \mathrm{a}$ is essential for the genome integrity and viability of pluripotent cells. Dev. Biol 363 (2012) pp. 62-73.

[11] Niwa, H. How is pluripotency determined and maintained? Development 134 (2007) pp. 635-646.

[12] Matsuda $\mathrm{K}^{1}$, Maruyama $\mathrm{H}$, Guo F, Kleeff J, Itakura J, Matsumoto $\mathrm{Y}$, Lander AD, Korc M. Glypican-1 is overexpressed in human breast cancer and modulates the mitogenic effects of multiple heparin-binding growth factors in breast cancer cells. Cancer Res. 61 (2001) pp. 5562-9.

[13] F. M. van den Berg, I. O. Baas, M. M. Polak, and G. J. Offerhaus Detection of p53 overexpression in routinely paraffin-embedded tissue of human carcinomas using a novel target unmasking fluid. Am J Pathol. 142 (1993) pp. 381-385.

[14] Arispe, N., Diaz, J. C., Simakova, O., and Pollard, H. B. (2008). Heart failure drug digitoxin induces calcium uptake into cells by forming transmembrane calcium channels. Proc. Natl. Acad. Sci. USA 105 (2008), pp. 2610-2615.

[15] Altamirano, J., Li, Y., DeSantiago, J., Piacentino, V., 3rd, Houser, S. R., and Bers, D. M. The inotropic effect of cardioactive glycosides in ventricular myocytes requires $\mathrm{Na}+-$ Ca2+ exchanger function. J. Physiol. 575 (2006), pp. 845854.
[16] Akera, T. Membrane adenosinetriphosphatase: A digitalis receptor? Science 198 (1977) pp. 569-574.

[17] V. Nahapetyan, S. Delos Santos, K. J. Crocker, D. Tobar, D. Nazarian, H. Chirishyan, G. Beltran, R. Dubin, L. Reque,, P. Singh, B. Cardona, G. Royce Bachinela, L. Sarkisyan, G. Zem, S. Oppenheimer A manual kinetic assay in a fixed yeast model for drug discovery American Journal of Applied Scientific Research 5 (2019) pp. 28-35.

[18] K. Crocker, J. Deleon, L. Telliyan, K. Aprelian, A. Rosenberg, N. Pouri, G. Beltran, V. Ramirez, D. Kaufman, A. Petrosyan, D. Nazarian, M. Magistrado, S. Matinian, D. Hanna, S. Eskandari, F. Atanante, A. Nerses, G. Zem, S. Oppenheimer. A Kinetic Assay for Drug Discovery: Part 2, Sodium Sulfate. American Journal of Applied Scientific Research (2020), accepted, in press.

[19] K. Germanovich, E. Alessandra Femiaq, C. Y. Cheng, N. Dovlatova, M. Cattaneo Effects of $\mathrm{pH}$ and concentration of sodium citrate anticoagulant on platelet aggregation measured by light transmission aggregometry induced by adenosine diphosphate Platelets, 29 (2018), pp. 21-26.

[20] V. M. Navarro, S. L. Walker, O. Badali, L. L. Ngo, S. Weerasinghe, M. Barajas, G. Zem, S. B. Oppenheimer Analysis of surface properties of fixed and live cells using derivatized agarose beads Acta Histochem, 104 (2002), pp. 99-106.

[21] D. Kolodkin-Gal, S. Romero, S. Cao, J. Clardy, R. Kolter, R. Losick D-amino acids trigger biofilm disassembly Science 30 (2010), pp. 627-629.

[22] Herstein, O. Steven Oppenheimer CSUN Magazine, no. 67 (2016), p. 20. 